\title{
Penerapan Customer Knowledge Management pada e-commerce Butik Gendis Fashion Muslim
}

\author{
Nur Chasanah \\ Jurusan Informatika, Fakultas Teknik, Universitas Jenderal Soedirman, Indonesia \\ Email: nur.chasanah@unsoed.ac.id
}

\begin{abstract}
Abstrak
Pengetahuan merupakan aset yang penting dalam sebuah organisasi. Dalam kegiatan transaksi bisnis, pengetahuan pelanggan menjadi elemen yang dapat digunakan untuk bersaing dalam dunia bisnis. Semakin banyaknya pelanggan pada butik gendis fashion muslim mengakibatkan pengelola mengalami kesulitan dalam melakukan manajemen pelanggan, sehingga walaupun pelanggan banyak namun tidak memberikan dampak yang signifikan, khususnya dalam pengelolaan pengetahuan pelanggan. Sehingga pada penelitian ini dilakukan implementasi model manajemen pengetahuan pelanggan pada e-commerce Gendis Butik dengan menggunakan pendekatan Soft System Methodology. Langkah-langkah yang dilakukan pada penelitian ini antara lain dengan mengetahui permasalahan, mencari solusi dengan menggambarkan proses transformasi perubahan, menghasilkan dan menerapkan konsep sebagai solusi dan mengimplementasikannya pada butik. Fitur-fitur yang diimplementasikan antara lain Customer Repository, Customer Satisfaction Survey dan Discussion Forums yang dapat dijadikan sebagai media untuk berbagi pengetahuan pelanggan sehingga dapat menghasilkan produk yang sesuai dengan kebutuhan pelanggan dan dapat meningkatkan pemasaran sehingga menjadikan bisnis dapat berjalan lebih efektif dan efisien dalam bersaing di dunia maya.
\end{abstract}

Kata kunci: butik, e-commerce, konsumen, manajemen.

\section{Implementation Customer Knowledge Management in e-commerce Gendis Fashion Muslim Boutique}

\begin{abstract}
Knowledge is an important asset in an organization. In business transaction activities, customer knowledge becomes an element that can be used to compete in the business world. The increasing number of customers in muslim fashion gendis boutiques resulted in managers having difficulty in managing customers, so that although many customers but did not give a significant impact, especially in the management of customer knowledge. So in this research conducted the implementation of customer knowledge management model in e-commerce Gendis Butik using soft system methodology approach. The steps taken in this study include knowing the problem, finding solutions by describing the process of transforming change, producing and applying concepts as solutions and implementing them in boutiques. The features implemented include Customer Repository, Customer Satisfaction Survey and Discussion Forums which can be used as a medium to share customer knowledge so that it can produce products that suit customer needs and can improve marketing so as to make businesses can run more effectively and efficiently in competing in cyberspace.
\end{abstract}

Keywords: boutique, customer, e-commerce, , management,

\section{PENDAHULUAN}

Pada era perkembangan teknologi yang sangat cepat saat ini, pelaku usaha dituntut untuk terus meningkatkan kreativitasnya dalam menjalankan usahanya, khususnya pada saat para pelaku usaha tersebut melakukan kegiatan transaksinya secara online. Semakin banyaknya pelaku usaha yang melakukan transaksinya secara online, diperlukan adanya upaya dan kreativitas yang lebih untuk meningkatkan penjualan agar bisnis memiliki nilai lebih dibandingkan dengan bisnis serupa dalam menjalankan bisnisnya secara online. Selain itu dengan pemanfaatan teknologi internet, diharapkan juga dapat meningkatkan hubungan pelanggan sehingga berdampak pada meningkatnya omset penjualan. Omset penjualan yang dimaksud adalah jumlah keseluruhan pendapatan yang dihasilkan oleh suatu bisnis pada kurun waktu tertentu [1]. 
Penjualan secara online memberikan dampak besar dengan dukungan teknologi yang dikenal sebagai $e$ commerce yang dapat menyempurnakan konsep direct marketing [2]. e-commerce yang banyak bermunculan saat ini bukan hanya sekedar menjalankan perniagaan, melainkan juga memberikan fokus kepada pelayanan konsumen serta kolaborasi pemanfaatan basis data konsumen yang dapat meningkatkan nilai dari e-commerce tersebut. Konsumen merupakan aset yang sangat penting bagi bisnis yang berjalan secara online karena persebaran informasi dapat lebih cepat dilakukan dan memberikan dampak yang sangat luas sehingga bisnis dapat dengan mudah melebarkan sayap di dunia bisnis secara online. Seperti hasil penelitian yang telah dilakukan oleh [3] menyatakan bahwa transaksi penjualan yang dilakukan secara online melalui e-commerce dapat memperluas jangkauan pemasaran dan mempermudah calon konsumen untuk melakukan transaksi, terutama untuk konsumen dari luar daerah. Konsumen merasa lebih praktis dan hemat waktu serta dapat melihat penilaian terhadap produk yang diminati sehingga dapat dengan mudah memperoleh produk yang diinginkan konsumen dan dapat meningkatkan omset penjualan yang terjadi secara online.

Pelanggan merupakan salah satu aset/komponen penting yang dapat mempengaruhi perkembangan bisnis [4]. Pelanggan merupakan pihak yang akan menerima tawaran produk atau membeli produk dan layanan yang ditawarkan. Pelanggan menjadi bagian yang penting, khususnya dalam transaksi yang dilakukan secara online. Pelanggan memiliki akses yang besar pada bermacam-macam produk dan produsen juga dapat dengan mudah dalam menghimpun database pelanggan secara elektronik. Namun di sisi yang lain, karena pelanggan dan produsen tidak bertemu secara langsung maka memungkinkan adanya kekeliruan baik dari sisi pelanggan maupun produsen. Dampak negatif yang cenderung merugikan pelanggan apabila produk yang dipesan tidak sesuai dengan yang ditawarkan, sedangkan pada sisi produsen dengan banyaknya jumlah pelanggan tidak dapat melakukan manajemen pengetahuan pelanggan yang berakibat dapat membuat produsen kehilangan konsumen tersebut [5].

Berdasarkan penelitian internal yang dilakukan oleh Brian Marshal, CEO dan Founder dari SIRCLO [6] terdapat tiga trend industri e-commerce yang perlu diantisipasi oleh brand atau pemilik usaha pada tahun 2020 ini, yaitu peningkatan daya beli dari pelanggan yang ada di luar pulau Jawa, pertumbuhan industri e-commerce Indonesia yang didominasi oleh penjualan ritel seperti fashion, dan pelanggan di era modern saat ini memiliki kebiasaan belanja dengan menggunakan platfom online. Pelanggan menjadi salah satu aset yang penting untuk dapat meningkatkan penjualan secara online, namun permasalahan yang biasa terjadi adalah banyaknya bisnis yang tidak melakukan pengelolaan terhadap pengetahuan pelanggan sehingga kesulitan untuk mendapatkan dan mempertahankan pelanggan.

Salah satunya yang terjadi pada Gendis Butik yang merupakan pelaku bisnis fashion yang saat ini menghadapi permasalahan dalam melakukan manajemen pengetahuan pelanggan. Semakin banyaknya jumlah pelanggan menjadikan Gendis Butik mengalami kesulitan untuk melakukan segmentasi pasar dan menghasilkan produk sesuai dengan kebutuhan pelanggannya. Selain itu semakin banyaknya kompetitor menjadikan Gendis Butik ingin terus berkembang salah satunya dengan memanfaatkan kecanggihan teknologi e-commerce. Kebutuhan akan website e-commerce dirasakan oleh pemilik butik ini yang harapannya dapat menjadikan butik lebih dapat melakukan pengelolaan pengetahuan pelanggan dan dapat menjadi lebih dekat dengan pelanggannya. Pemilik Gendis Butik menyadari pentingnya pelanggan sebagai aset yang harus diperhatikan sehingga diperlukan adanya sebuah inovasi pemanfaatan e-commerce.

Harapan dari e-commerce yang dapat mengatasi permasalahan tersebut adalah e-commerce yang dapat digunakan sebagai media untuk melakukan manajemen pengetahuan pelanggan sehingga dapat mempermudah melakukan pelayanan secara real time dan melakukan pengelolaan pengetahuan pelanggan. Selain itu dengan adanya manajemen pengetahuan pelanggan juga diharapkan dapat menghasilkan pengetahuan baru bagi Gendis Butik untuk dapat menghasilkan produk yang sesuai dengan kebutuhan pelanggan dan dapat meningkatkan pemasaran sehingga menjadikan bisnis dapat berjalan lebih efektif dan efisien dalam bersaing di dunia maya.

\section{METODE PENELITIAN}

Penelitian ini dilakukan di Gendis Butik, Purbalingga, Indonesia. Metode penelitian yang digunakan yaitu menggunakan pendekatan Soft System Methodology (SSM) dimana metode tersebut memiliki 7 tahapan yang selanjutnya disesuaikan dengan studi kasus dan divisualisasikan dengan kerangka penyelesaian masalah pada gambar 4. Pada tahapan pertama yaitu Enter The Problem Situation, dilakukan identifikasi dan deskripsi singkat tentang kondisi yang terjadi pada Gendis Butik yang saat ini sedang terjadi, dan juga mendefininsikan stakeholder yang terlibat dalam Gendis Butik. Tahapan selanjutnya adalah Express The Problem Situation. Tahapan kedua ini memberikan gambaran mengenai permasalahan yang ada pada kondisi sebenarnya serta mengumpulkan data dan informasi pada Gendis Butik yang selanjutnya dituangkan dalam gambaran Rich Picture. Pada tahap ini juga akan dilakukan identifikasi Customer Knowledge Goals pada Gendis Butik, serta identifikasi kebutuhan butik e-commerce. 
Tahapan ketiga yaitu membuat Root Definition (RD) yaitu memberikan gambaran proses (transformasi) untuk mencapai tujuan organisasi, dimana Gendis Butik memiliki tujuan yaitu mencapai profit tinggi dengan efisien dan efektif. Analisis RD dilakukan dengan menggunakan CATWOE, yang merupakan singkatan dari Customers; pihak yang mendapatkan manfaat dari kegiatan transformasi ini. Pada Gendis Butik yang berlaku sebagai customers yaitu pemilik butik, karyawan butik, customer (pembeli / calon pembeli) dan member (pelanggan butik). Actors; pihak yang menfasilitasi terjadinya transformasi ini kepada customers. Pihak yang berperan sebagai actors pada Gendis Butik yaitu pemilik butik dan karyawan butik. Transformation; menggambarkan perubahan keadaan yang ingin dicapai, dimulai dari keadaan awal dan hasil yang akhir yang diharapkan. Pada Gendis Butik, keadaan awalnya yaitu Gendis Butik belum memanfaatkan pengetahuan pelanggan dengan maksimal dan transformasi yang ingin dicapai yaitu Genis Butik dapat memanfaatkan pengetahuan pelanggan untuk mengembangkan produk maupun pelayanan. Weltanshauung (World View); pandangan umum yang menjadi alasan transformasi tersebut perlu dilakukan. Owner; pihak yang memiliki dan dapat menghentikan transformasi tersebut. Pada penelitian ini yang berlaku sebagai Owner adalah pemilik butik. Yang terakhir adalah Environmental Constraints; faktor lingkungan yang memperngaruhi transformasi tapi tidak mengendalikan sistem.

Pada tahapan keempat ini merupakan Build Conceptual Models of The Systems Names in The Root Definition, dilakukan pembuatan model yang berdasar pada hasil dari tahapan ketiga. Model konseptual yang dihasilkan merupakan representasi grafis dari perspektif pada Root Definition yang telah dihasilkan. Pada penelitian ini konseptual model akan direpresentasikan dalam fitur-fitur $e$-commerce yang mendukung Customer Knowledge Management. Tahap selanjutnya adalah Compare the Models with the Real World Actions, kegiatan yang dilakukan pada tahapan kelima ini adalah membandingkan model konseptual yang telah dibuat dengan gambaran Rich Picture yang sudah dibuat pada tahapan kedua yang menggambarkan kondisi pada Gendis Butik.

Tahapan keenam, Defines Possible Changes which are Desirable and Feasible, melakukan perubahan dalam bentuk rekomendasi yang akan diimplementasikan pada Gendis Butik e-commerce sehingga dapat digunakan sebagai aksi untuk menyelesaikan permasalahan. Pada tahapan terakhir, Take Action to Improve the Problem Situation, adalah mengambil tindakan untuk menyelesaikan permasalahan. Kegiatan yang dilakukan sesuai dengan solusi pemecahan masalah atau perubahan yang akan dilakukan sesuai dengan hasil yang didapatkan dari tahapan sebelumnya sehingga permasalahan dapat diselesaikan dan memberikan kondisi yang lebih baik bagi organisasi. Pada tahap ini dilakukan implementasi Customer Knowledge Management pada e-commerce butik.

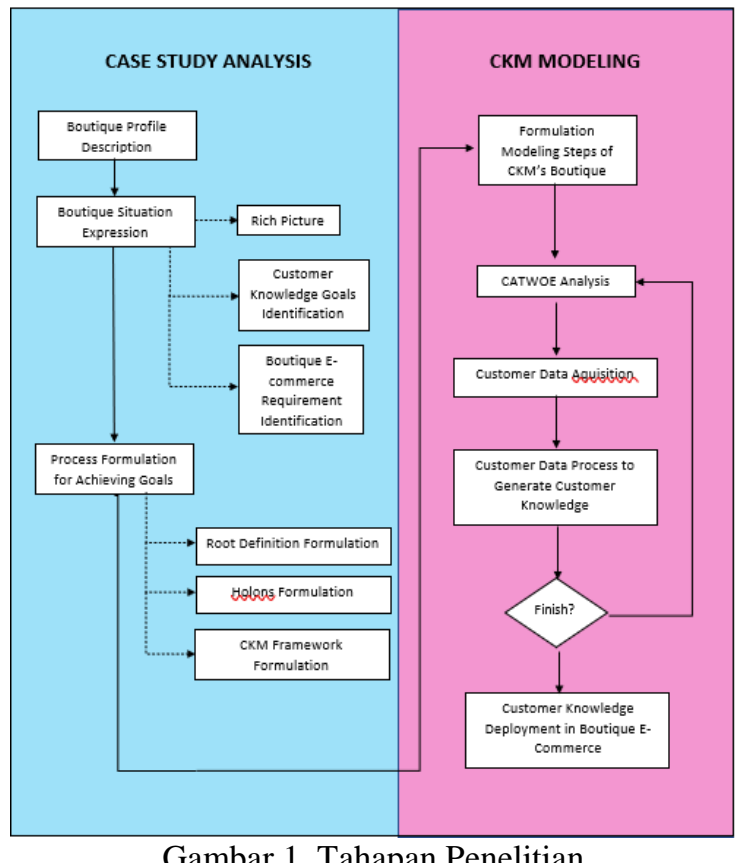

Gambar 1. Tahapan Penelitian

Dari kerangka penyelesaian masalah pada Gambar 1 diharapkan dapat menghasilkan rekomendasi dan implementasi yang sesuai untuk situasi yang ada pada Gendis Butik, sehingga Gendis Butik dapat memanfaatkan dengan maksimal sumber daya yang ada untuk mengembangkan produk, pelayanan dan kemudahan dalam akses e-commerce. 


\section{HASIL DAN PEMBAHASAN}

Penelitian ini mengimplementasikan manajemen pengetahuan pelanggan (CKM) yang diterapkan dalam $e$ commerce Gendis Butik sesuai dengan kerangka penyelesaian masalah yang telah dirancang sebelumnya. Implementasi CKM membantu Gendis Butik dalam melakukan kegiatan bisnisnya dengan menggunakan $e$ commerce yang dapat meningkatkan kualitas layanan dan menjalin hubungan dengan pelanggan semakin baik sehingga tercipta pengetahuan baru untuk dapat meningkatkan penjualan dan pemasaran Gendis Butik melalui $e$ commerce. Berikut adalah hasil dari penelitian ini.

\subsection{Enter The Problem Situation}

a. Deskripsi profil butik

Pada tahap pertama ini diperoleh informasi mengenai profile Gendis Butik. Butik ini berjalan dalam bidang fashion dan melakukan penjualan secara offline serta online hanya melalui marketplace. Pendataan pelanggan secara umum belum dilakukan, namun sudah ada data untuk member yang disimpan namun belum dikelola untuk dijadikan sebagai pengetahuan baru yang dapat digunakan untuk mengembangkan produk dari Gendis Butik.

b. Stakeholder Gendis Butik

Stakeholder yang terdapat dalam gendis butik antara lain : a) Pemilik butik, yang berperan dalam pengelolaan seluruh kegiatan dalam butik. b) Karyawan butik, yang berperan melayani customer, c) Customer, yang berperan sebagai sumber daya pemasukan butik, dan d) Member, customer yang mendapatkan previllage dan menjadi pelanggan tetap dalam butik.

4.2. Situasi dan Kondisi Gendis Butik

\section{a. Rich Picture}

Pada tahapan ini dihasilkan gambaran kondisi yang terjadi pada Gendis Butik. Kondisi ini disampaikan dalam Rich Picture yang menggambarkan kondisi secara lebih detail terkait stakeholder dan perannya, serta permasalahan yang terjadi pada Gendis Butik saat ini, seperti yang digambarkan pada Gambar 2 berikut ini.

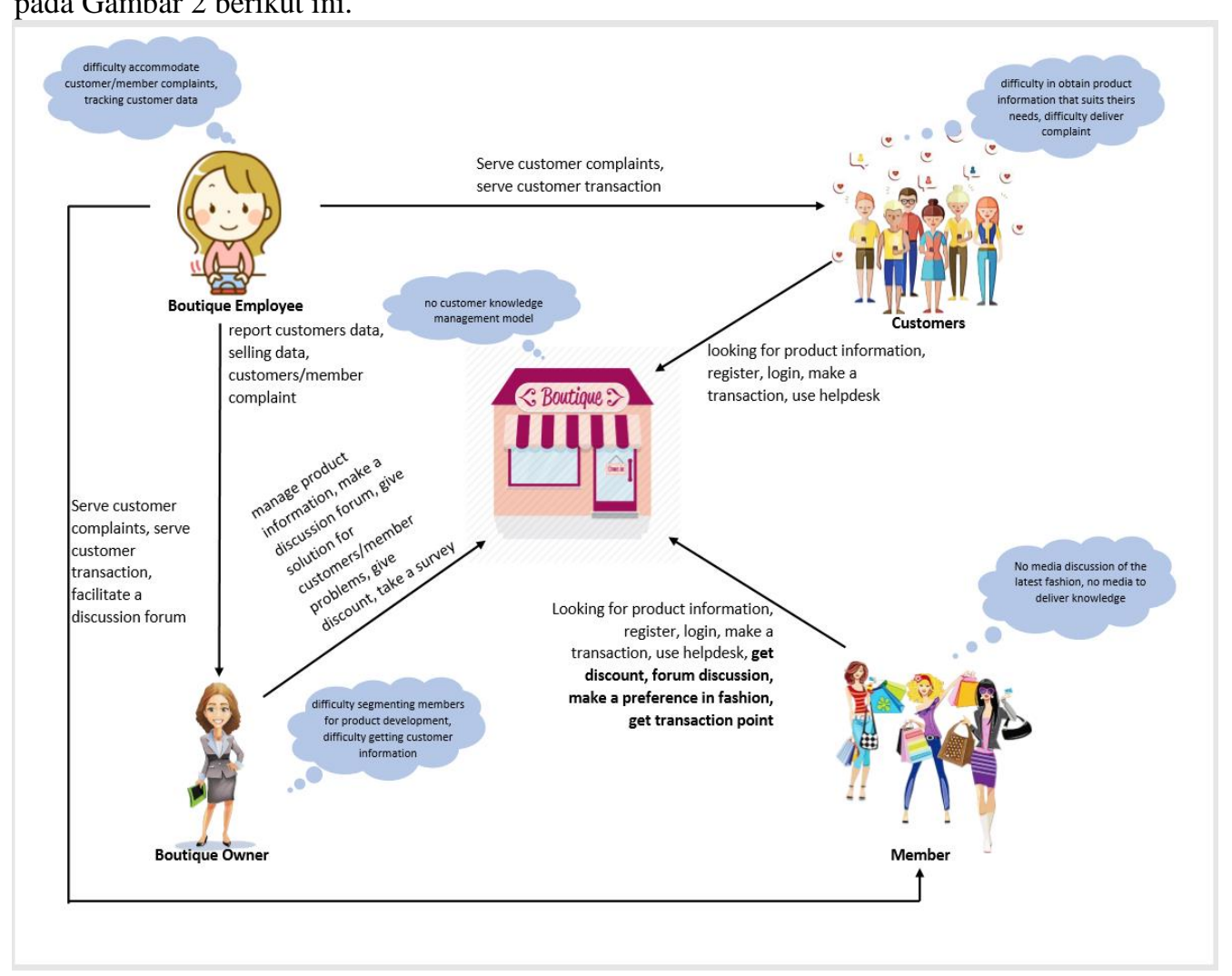

Gambar 2. Rich Picture CKM pada Gendis Butik

Pada gambar 2, Rich picture memberikan pemetaan tentang keterkaitan masing-masing aktor, kegiatan apa yang dapat dilakukan tiap aktor dan keadaan yang menggambarkan kebutuhan masingmasing aktor yang belum terpenuhi. Stakeholder yang terdapat pada penelitian ini yaitu pemilik butik, karyawan butik, konsumen, member butik. Pada gambar tersebut juga dijelaskan kendala yang dihadapi 
dari masing-masing stakeholder, seperti pemilik butik mengalami kesulitan melakukan segmentasi member untuk meningkatkan kualitas produk dan kesulitan mendapat informasi konsumen.

b. Customers Knowledge Goals

Selain menggunakan rich picture, situasi dalam butik juga diuraikan menjadi identifikasi customer knowledge goals, dimana goals dari customer knowledge management ini adalah memaksimalkan pengetahuan yang dimiliki oleh customer ataupun member untuk meningkatkan kualitas produk, sehingga produk dapat lebih sesuai dengan kebutuhan customer dan member. Hasil dari pemaksimalan pengetahuan ini adalah segmentasi pengetahuan yang nantinya akan dimanfaatkan oleh pemilik butik untuk melakukan pengembangan produk.

c. Boutique e-commerce Requirements

Pada ekspresi situasi juga menguraikan identifikasi kebutuhan butik e-commerce, kebutuhan tersebut didapatkan dari wawancara dan juga pengamatan terhadap sistem yang saat ini berjalan di Gendis Butik.

4.3 Formulate Root Definitions of Relevant Systems

a. Formulate Root Definition

Pada tahap ini yang dilakukan adalah memproses formulasi Root Definition agar dapat mencapai tujuan penelitian yaitu implementasi CKM pada e-commerce. Analisis Root Definition dilakukan dengan menggunakan analisis CATWOE yang terdiri dari Customer, Actors, Transformation, Weltanshauung, Owner dan Environment. Analisis CATWOE yang telah dilakukan disampaikan pada Tabel 1. berikut:

Tabel 1. Analisis CATWOE

\section{$1 \quad$ Holon 1}

Customer

Actors

Transformation

Weltanshauung

Owner

Environment

2 Holon 2

Customer

Actors

Transformation

Weltanshauung

Owner

Environment

$3 \quad$ Holon 3

Customer

Actors

Transformation

Weltanshauung

Owner

Environment

4 Holon 4

Customer

Actors

Transformation
Pengalaman serta usulan kebutuhan customer dapat disimpan dan dijadikan sebagai pengetahuan untuk melakukan pengembangan produk.

Customer, Member, Pemilik Butik, Karyawan Butik

Pemilik Butik, Customer, Member

Customer dan member yang sebelumnya tidak dapat menyampaikan pengalaman terhadap produk menjadi dapat menyampaikan pengalaman

Memaksimalkan pengetahuan customer dan member

Pemilik Butik

Kesulitan merekam pengetahuan customer dan member

Pengetahuan member dapat dijadikan segmentasi bagi pengembangan produk

Member, Pemilik Butik

Member, Pemilik Butik

Data yang sebelumnya masih acak menjadi pengetahuan yang tersegmentasi

Memaksimalkan pemanfaatan pengetahuan yang didapat dari member

Pemilik Butik

Kesulitan melakukan segmentasi member untuk melakukan pengembangan produk

Butik dapat mengetahui keluhan dan melakukan tindak lanjut yang tepat untuk menyelesaikan permasalahan customer dan member

Customer, Member, Pemilik Butik

Customer, Member, Pemilik Butik, Karyawan

Keluhan customer dan member yang sebelumnya tidak tersampaikan dapat tersampaikan ke karyawan dan pemilik

Memfasilitasi keluhan customer dan member agar dapat ditindaklanjuti

Pemilik Butik

Kesulitan penyampaian keluhan oleh customer dan member

Butik dapat menggali pengalaman dan pengetahuan member tentang fashion

Member, Pemilik Butik

Pemilik Butik, Karyawan, Member

member yang sebelumnya belum memiliki media informasi untuk bertukar pengetahuan dan pengalaman menjadi terfasilitasi kebutuhan 
Weltanshauung

akan informasi fashion

Owner

Menyediakan media diskusi untuk bertukar pengetahuan dan pengalaman antara member, karyawan dan pemilik butik

Environment Butik

Belum adanya media diskusi fashion terkini yang berhubungan dengan butik e-commerce

\section{b. Formulation Modelling Steps of CKM's Boutique}

Setelah dihasilkan Root Definition, kemudian dibuat model implementasi CKM pada Gendis Butik e-commerce. Tahapan model divisualisasikan pada Gambar 3 berikut ini.

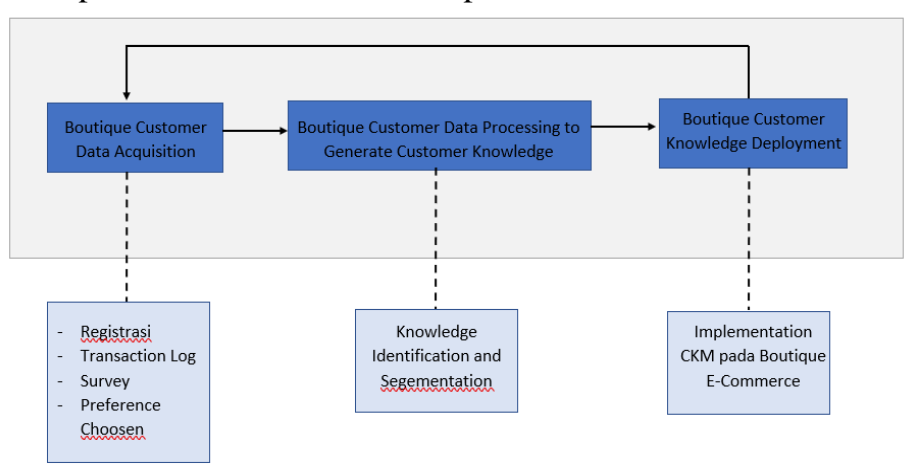

Gambar 3. Model CKM Gendis Butik

Formulasi model CKM yang digambarkan pada penelitian ini dimulai dari tahapan Akuisisi data pelanggan gendis butik. Kegiatan yang dilakukan pada tahapan ini adalah melakukan akuisisi data pelanggan dari registrasi yang telah dilakukan oleh pelanggan, data transaksi, data survey dan data pemilihan preference yang dilakukan oleh pelanggan. Selanjutnya melakukan proses pengolahan data pelanggan menjadi pengetahuan pelanggan dengan kegiatan identifikasi dan segmentasi pengetahuan. Kemudian pada tahapan pengembangan pengetahuan pelanggan butik dilakukan implementasi CKM pada gendis butik e-commerce dengan rencana pembuatan fitur-fitur yang akan dijadikan sebagai media untuk menyelesaikan permasalahan.

\subsection{Build Conceptual Models of The Systems Names in The Root Definition}

Pada tahapan keempat ini dilakukan pembuatan model yang berdasar pada hasil dari tahapan ketiga. Model konseptual yang dihasilkan merupakan representasi grafis dari perspektif pada Root Definition yang telah dihasilkan.

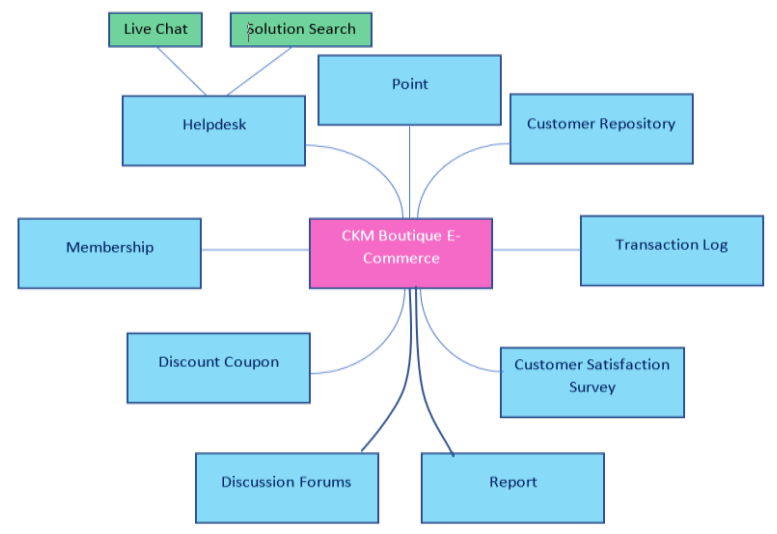

Gambar 4. Konceptual Model CKM Gendis Butik

Konseptual model pada gambar 4 menampilkan CKM Boutique e-commerce ini memiliki beberapa fitur yang akan mendukung CKM Goals. Fitur tersebut yaitu : Customer Repository, Transaction Log, Customer Satisfaction Survey, Discussion Forums, Discount Coupon, Membership, Helpdesk, Point, dan Report. Detail fitur yang dihasilkan sebagai berikut:

a. Customer Repository 
Fitur ini adalah fitur yang memfasilitasi penyimpanan data customer dan member sehingga data tersebut akan terkelola dengan baik, serta dapat menghasilkan pengetahuan yang bermanfaat bagi pemilik butik, dimana data customer dan member akan disegmentasi berdasarkan parameter tertentu. Selain itu fitur ini juga berguna bagi pemilik butik untuk mendapatkan informasi detail customer dan member.

b. Transaction Log

Fitur ini berguna untuk mencatat segala transaksi yang terjadi pada e-commerce butik. Fitur ini berguna bagi karyawan untuk melakukan pelacakan data apabila terjadi permasalahaan pada transaksi customer atau member

c. Customer Satisfaction Survey

Fitur ini akan melakukan survey kepada member e-commerce mengenai kepuasan member terhadap kualitas produk, pelayanan, kemudahan e-commerce dan sebagainya. Survey ini berguna untuk peningkatan kualitas e-commerce dan pengembangan produk.

d. Discussion Forums

Fitur ini bertujuan memfasilitasi member untuk berdiskusi topik tertentu mengenai fashion. Fitur ini dapat diakses oleh member, pemilik butik dan karyawan.

e. Discount Coupon

Fitur ini menyediakan fasilitas kupon diskon yang dibagikan oleh e-commerce butik kepada customer atau member. Tujuan dari discount coupon ini adalah untuk menarik customer atau member agar tetap berbelanja di Gendis Butik.

f. Membership

Fitur ini dibuat dengan tujuan untuk membedakan customer biasa dengan costumer yang telah mendaftar sebagai member, dimana member akan mendapatkan fasilitas dan keunutungan dibandingkan dengan customer. Perbedaan fasilitasnya antara lain, member akan mendapatkan fasilitas : forum discussion, fashion preference, point, discount, point, sedangkan customer tidak.

g. Helpdesk

Helpdesk merupakan fitur pelayanan bantuan bagi customer maupun member, dimana helpdesk ini berupa fitur pencarian solusi dan live chat. Pada fitur pencarian solusi customer atau member dapat mengetikan permasalahan yang dialami, serta ditampilkan juga permasalahan yang sering muncul. Pada fitur live chat, customer atau member dapat berkomunikasi langsung dengan karyawan butik. Fitur ini dibuat dengan tujuan untuk memelihara kenyamanan dan kepuasan customer atau member ketika terjadi kendala saat menggunaan e-commerce.

h. Point

Point adalah salah satu fitur yang dikhususkan untuk member, dimana member akan mendapatkan point ketika melakukan transaksi. Point tersebut akan diakumulasi dan dapat ditukarkan. Fitur ini dibuat dengan tujuan untuk menarik member agar memiliki kecenderungan berbelanja di Gendis Butik.

i. Report

Report adalah fitur utama dari CKM e-commerce Butik, dimana fitur ini akan menampilkan laporan dalam bentuk segementasi pengetahuan yang dimiliki oleh CKM. Segementasi pengetahuan tersebut berguna untuk pemilik butik dalam pengembangan produk agar lebih tepat sasaran.

\subsection{Compare the Models with the Real World Actions}

Kegiatan yang dilakukan pada tahapan kelima ini adalah membandingkan model konseptual yang telah dibuat dengan gambaran Rich Picture yang sudah dibuat pada tahapan kedua. Perbandingan antara real world dan implementasi manajemen pengetahuan pelanggan dapat dilihat pada Tabel 2 berikut ini.

Tabel 2. Perbandingan Real World dan CKM Action

\section{Real World}

Tidak ada model manajemen pengetahuan

Pelanggan sulit dalam mendapatkan informasi produk yang sesuai dengan kebutuhan mereka

Keluhan pengiriman pelanggan sulit, Karyawan Butik Menyediakan media untuk keluhan pelanggan sulit dalam mengakomodasi keluhan pelanggan /

anggota
Membuat model manajemen pengetahuan pelanggan

Memberikan informasi produk sesuai dengan

preferensi yang dipilih anggota 


\begin{tabular}{ll}
\hline \multicolumn{1}{c}{ Real World } & \multicolumn{1}{c}{ CKM Action } \\
\hline Tidak ada diskusi media tentang mode terbaru & Menyediakan forum diskusi untuk anggota \\
$\begin{array}{l}\text { Tidak ada media untuk memberikan pengetahuan } \\
\text { anggota, Karyawan Butik sulit melacak data } \\
\text { pelanggan, Pemilik Butik sulit mendapatkan } \\
\text { informasi pelanggan }\end{array}$ & $\begin{array}{l}\text { Menyediakan repositori untuk mengakomodasi } \\
\text { pengetahuan anggota }\end{array}$ \\
$\begin{array}{l}\text { Pemilik Butik sulit dalam mmentasi pengetahuan } \\
\text { untuk pengembangan produk }\end{array}$ & $\begin{array}{l}\text { Memberikan laporan untuk menampilkan } \\
\text { pengetahuan tersegmentasi }\end{array}$ \\
\hline
\end{tabular}

4.6 Defines Possible Changes which are Desirable and Feasible

Tahapan keenam ini adalah melakukan perubahan yang akan dilakukan dengan memberikan rekomendasi untuk menyelesaikan permasalahan pada Gendis Butik e-commerce. Rekomendasi yang diberikan untuk menyelesaikan permasalahan pada penelitian ini antara lain:

a) Gendis Butik perlu melakukan pengelolaan data dan pengetahuan pelanggan untuk dapat memiliki hubungan yang lebih dekat dengan pelanggannya.

b) Gendis butik perlu menyediakan media untuk dapat melakukan komunikasi secara langsung dengan pelanggan sehingga pelanggan dapat menyampaikan pengetahuannya, sehingga pengetahuan pelanggan dapat dikelola dan menghasilkan pengetahuan baru yang dapat bermanfaat bagi pengembangan produk pada Gendis Butik.

c) Gendis butik sebaiknya secara berkala melakukan survey kepada pelanggan untuk dapat mengetahui kebutuhan pelanggan dan trend pasar yang saat ini banyak diminati oleh pelanggan.

d) Gendis Butik perlu meningkatkan pelayanan helpdesk sehingga pelanggan dapat dengan mudah menemukan solusi dari permasalahan yang dihadapi dan cepat memperoleh respon dari butik sehingga dapat meningkatkan kedekatan hubungan pelanggan dengan gendis butik.

e) Gendis Butik sebaiknya bukan hanya mengelola data transaksi bisnisnya untuk membuat laporan keuangan, tapi juga mengolah data transaksi dari masing-masing pelanggan dengan membuat laporan segmentasi pelanggan sehingga dapat menghasilkan pengetahuan baru yang dapat bermanfaat bagi pengembangan produk dan memenuhi kebutuhan pelanggan.

\subsection{Take Action to Improve the Problem Situation}

Pada tahapan terakhir ini adalah mengambil tindakan untuk menyelesaikan permasalahan. Kegiatan yang dilakukan sesuai dengan solusi pemecahan masalah atau perubahan yang akan dilakukan sesuai dengan hasil yang didapatkan dari tahapan sebelumnya sehingga permasalahan dapat diselesaikan dan memberikan kondisi yang lebih baik bagi organisasi. Manajemen Pengetahuan Pelanggan pada Gendis Butik e-commerce diimplementasikan dengan adanya fitur-fitur yang digambarkan sebagai berikut:

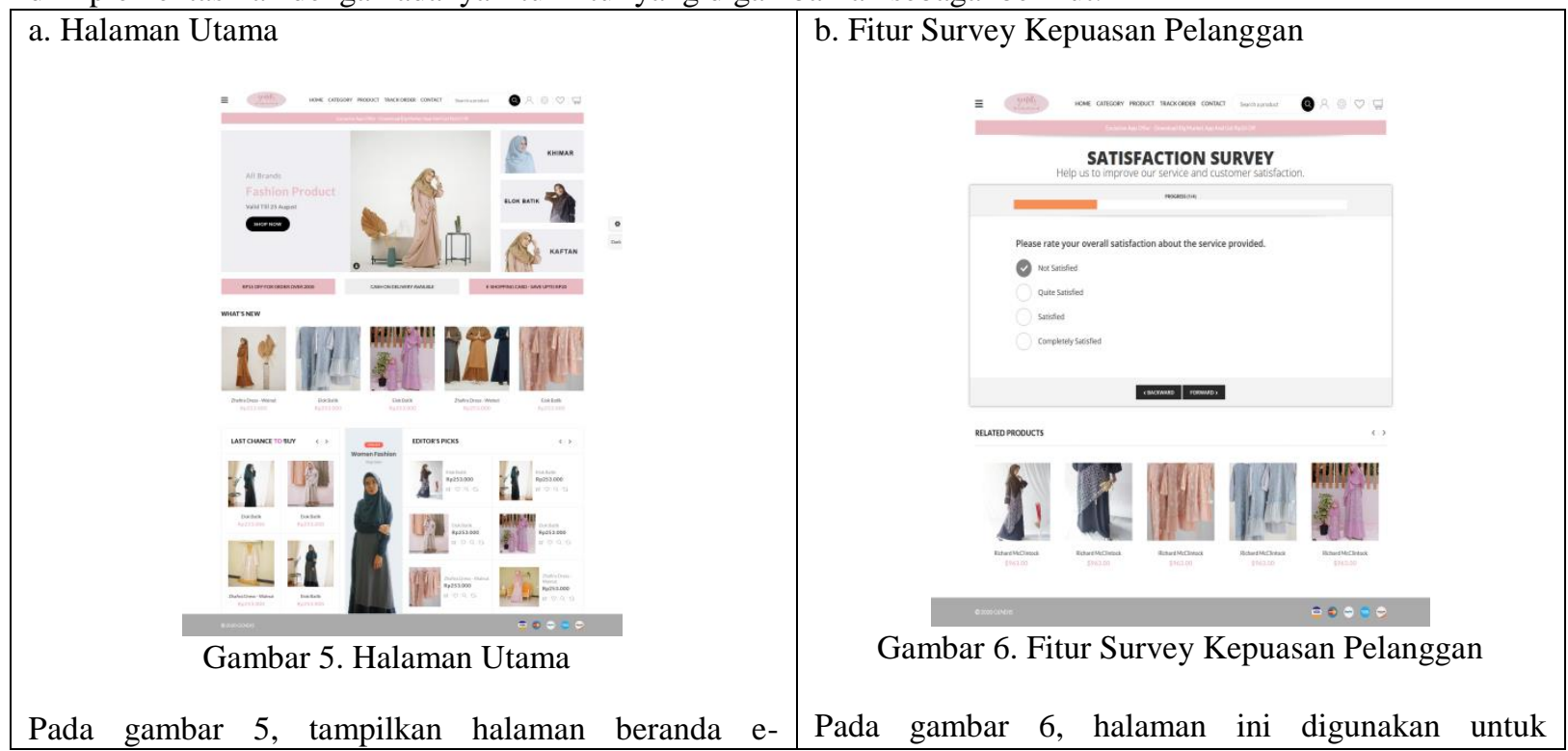




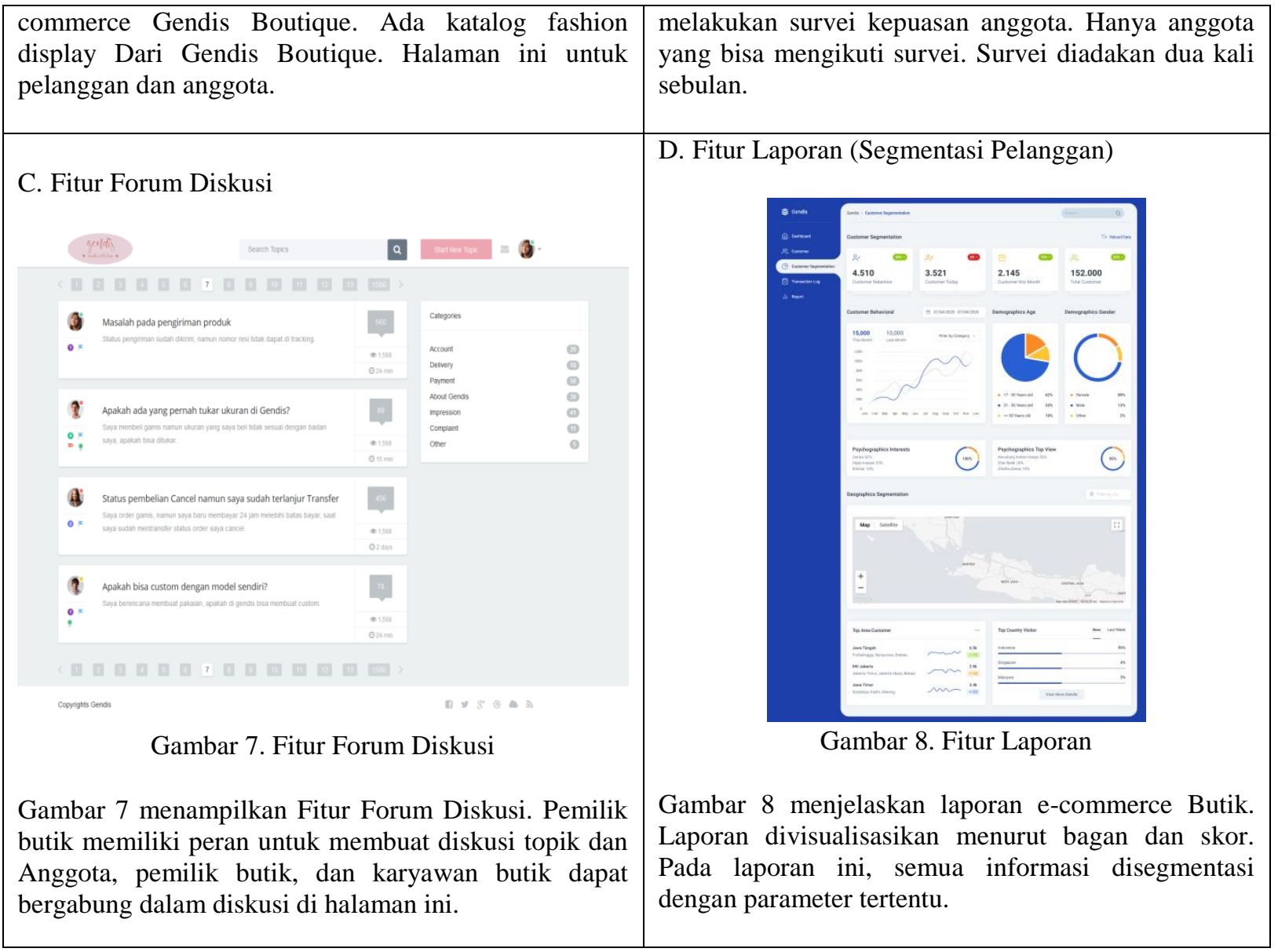

\section{KESIMPULAN}

Pengetahuan pelanggan merupakan aset yang penting dalam suatu organisasi, khususnya Gendis Butik yang sudah memiliki banyak pelanggan, sehingga diperlukan implementasi manajemen pengetahuan pelanggan pada e-commerce, yang dapat memghasilkan segmentasi pengetahuan pelanggan yang dapat menghasilkan pengetahuan baru. Pengetahuan baru dihasilkan dari Customer Repository, Transaction Log, Customer Satisfaction Survey, Discussion Forum, Disscount Coupon, Membership, Helpdesk, Point and Report yang dapat mengelola pengetahuan pelanggan dan dapat meningkatkan hubungan pelanggan. Dari fitur-fitur yang telah dihasilkan pada e-commerce menunjukkan fungsi-fungsi yang dapat dimanfaatkan oleh Gendis Butik untuk mengelola pengetahuan pelanggan dan dapat meningkatkan pemasaran sehingga menjadikan bisnis dapat berjalan lebih efektif dan efisien.

\section{DAFTAR PUSTAKA}

[1] Nissa Nurfitria dan Retno Hidayati. Analisis Perbedaan Omset Penjualan Berdasarkan Jenis Hajatan dan Waktu (Studi Pada Catering Sonokembang Semarang). Jurnal Liquidity, Vol. 1 (nissanurfitria@yahoo.com, di akses 02 Oktober 2013)

[2] Adhi Prasetio. Jualan Online. 2012. Jakarta : Mediakita.

[3] Celestino, Martha L. 1999. Electronic Commerce. [hal. www]. World Trade. Februari, Sumber http://proquest.umi.com/pqdweb?TS=91793...\&Fmt=3\&Sid=1\&Idx=7\&Deli=1\&RQT=309\&Dtp=1 (diakses 2 Februari 1999)

[4] McKinzie, B. 1999. Internet Poses New Challenges to Traditional Retaillers. [hal. www]. Enterprise. Vol 28, issue 34. Sumber dari http://gw2.epnet.com/ fulltext.asp?resul...= e\%2dcommerce\%20and\%20control\&fuzzyTerm=(diakses 3 Maret 1999)

[5] Nugroho, Adi (2007), "e-commerce: memahami perdagangan modern di dunia maya", Bandung: Informatika. 
[6] Dya Ayu Wulansari. Pengaruh Penjualan Online Terhadap Omset Penjualan Butik Zieta Desa Sewulan Kec. Dagangan Kab. Madiun. Jurnal Equilibrium, Vol. 3, No 2. Juli 2015.

[7] Sunardi dan Anita Primastiwi. Pengantar Bisnis: Konsep, Strategi dan Kasus. Yogyakarta : CAPS. 2015

[8] Sri Anafarhanah. Peran Pengawasan Konsumen Dalam Transaksi Bisnis Online. Jurnal AlHadharah. Volume 16 Nomor 32 Tahun 2017. E-ISSN 2579-986X.

[9] Siahaan, Hotlan. (2008) "Customer Relationship Manajemen (CRM) Sebagai Sarana Meraih Image Positif untuk Prpustakaan. Jurnal Studi Perpustakaan dan Informasi”, Universitas Sumatera Utara Vol. 4, No. 2

[10] CNN Indonesia. 2020. https://www.cnnindonesia.com/teknologi/20200205204206-206-472064/tren-danpeluang-industri-e-commerce-di-indonesia-2020 Diakses pada tanggal 26 Juni 2020 pukul 15.02 WIB

[11] Despin Yuliance. 2016. Penerapan e-commerce Dalam Meningkatkan Daya Saing Usaha Pada Butik Despin Yuliance. Konferensi Mahasiswa Sistem Informasi. Vol 4, Nomor 1, hal. 363-368. Lampung: STMIK Pringsewu.

[12] Wilde, Silvio (2011). Customer Knowledge Management: Improving Customer Relationship through Knowledge Application.p.48. Springer. New York. ISBN: 978-3-642-16474-3

[13] Chasanah, Nur. 2018. Implementasi Knowledge Management dengan Pendekatan Soft System Methodology (Studi Kasus: Kampung Marketer, Purbalingga). Prosiding Nasional Rekayasa Teknologi Industri dan Informasi XIII Tahun 2018 (ReTII). Sekolah Tinggi Teknologi Nasional, Yogyakarta. ISSN: 1907-5995. 